\title{
Non-Competitive NMDA-Receptor Antagonists and Anoxic Degeneration of the ERG B-Wave In Vitro
}

\author{
JUN C. HUANG, THOMAS E. SALT, MARY J. VOADEN AND JOHN MARSHALL \\ London
}

\begin{abstract}
Summary
Studies have been undertaken to see if the non-competitive NMDA antagonists, ketamine, MK-801 and dextromethorphan would preserve the b-wave of the electroretinogram (ERG) in vitro. The drugs had no effect on the ERG b-wave, nor prolonged its survival postmortem. The present results support previous evidence suggesting that NMDA-receptors are not involved directly in synaptic transmission between photoreceptors and $\mathrm{ON}$-bipolar cells. Further, loss of the b-wave in postmortem anoxia does not appear to be mediated via NMDA-receptors.
\end{abstract}

During studies on survival of phototransduction in postmortem rat and human retinae, we have found that, following regeneration of visual pigment, PIII responses of the ERG could be recovered to a large extent in previously-bleached, freshly isolated rat retinae, and partially recovered in human retinae up to 58 hours postmortem. ${ }^{1-3}$ We also noted that the b-wave was apparent not only in the rat retina but also in some human retinae up to 43 hours postmortem..$^{2.3}$ Its survival, however, was poor compared with PIII. The b-wave is an indicator of synaptic transmission between photoreceptors and second order retinal neurones, principally, if not totally, ON-bipolar cells. ${ }^{4.5}$ Excitatory amino acids mediate the transmission and, in man as well as lower order vertebrates, L-glutamate is likely to play a major role. ${ }^{6-8}$ Recently, it has been reported that dextromethorphan, a non-competitive antagonist of excitatory amino acid receptors of the NMDA (N-methyl-D-aspartate) type, can protect the rabbit retina against ischaemic damage and preserve the b-wave in vivo. ${ }^{9}$ Furthermore, NMDA is known to cause spreading depression ${ }^{10}$ and to have neurotoxic actions $^{11}$ in the retina in vitro, and both of these actions can be blocked by non-competitive NMDA-receptor antagonists such as ketamine or MK-801 [(+)-5-methyl-10, 11dihydro-5H-dibenzo[a,d]cyclo-hepten-5,10imine]. Therefore, we considered it possible that loss of the b-wave from the retina postmortem might also be due to anoxic damage involving NMDA receptors. To investigate this, we have attempted to protect rat retinae against postmortem damage by pretreating rats with systemic injections of ketamine or dextromethorphan, and we have also studied the effects of these drugs and MK-801 on the ERG b-wave in vitro.

\section{Materials and Methods}

\section{Medium}

Earle's medium (composition in $\mathrm{mM}-\mathrm{NaCl}$ 116, $\mathrm{KCl} 5.4, \mathrm{NaHCO}_{3} 26.2, \mathrm{NaH}_{2} \mathrm{PO}_{4}$ 1.0, $\mathrm{MgSO}_{4} 0.8, \mathrm{CaCl}_{2} 1.8$ and glucose 5.5 ) was pregassed with a moistened mixture of $95 \%$ $\mathrm{O}_{2} / 5 \% \mathrm{CO}_{2}$ and had a final $\mathrm{pH}$ of 7.2 at room temperature. Fetal calf serum was added to a concentration of $2 \%$ for perfusion studies. 


\section{The electroretinogram}

Isolated retinae were placed, ganglion cell layer downwards, onto Whatman No. 1 filter paper and both surfaces of the tissue/filter paper preparation were perfused at $7 \mathrm{ml} / \mathrm{min}$ with $400 \mathrm{ml}$ of recirculating perfusion medium. The medium was gassed continuously with a moistened mixture of $95 \% \mathrm{O}_{2} / 5 \%$ $\mathrm{CO}_{2}$ and maintained at $35^{\circ} \mathrm{C}$. Photoresponses were recorded with cotton wick and $\mathrm{Ag} / \mathrm{AgCl}$ electrodes, connected to a high input impedance preamplifier with a band pass of 0-200 Hz. A $1.5 \mathrm{~mm}$ diameter L.E.D. stimulus, wavelength $550 \mathrm{~nm}$, was used. Duration was $0.2 \mathrm{sec}$. and maximum intensity (log $\mathrm{I}=0) 2.0 \times 10^{4}$ quanta/um ${ }^{2}$.

\section{Application of ketamine, $M K-801$ and dextromethorphan}

(1) Pretreatment of rats with ketamine and dextromethorphan:

Female albino Wistar rats, weighing 200 to 300 grams, were maintained in total darkness overnight before use. Some animals were injected intraperitoneally with $100 \mathrm{mg} / \mathrm{kg}$ ketamine $^{12}$ under dim red light, and after approximately five minutes they had lost their righting and other reflexes. Other animals were injected with $40 \mathrm{mg} / \mathrm{kg}$ dextromethorphan $^{13}$ and after 10 minutes the animals, together with the control ones, were anaesthetised with ether. All three groups were then killed by cervical dislocation, and the enucleated eyes stored at room temperature for the times indicated in the text. The Guiding Principles in the Care and Use of Animals (DHEW publication, NIH 80-23) were followed throughout.

(2) Application of ketamine, MK-801 and dextromethorphan in vitro:

Ketamine (final concentration 150 to $300 \mu \mathrm{M}),{ }^{14} \mathrm{MK}-801(100$ to $200 \mu \mathrm{M}){ }^{15}$ or dextromethorphan $(100 \text { to } 800 \mu \mathrm{M})^{16}$ was added to the perfusion medium during measurement of the ERG. In these experiments control responses to light stimuli were recorded within 5 minutes of the death of the animal.

\section{Application of $A P B$ in vitro}

For comparison, the effect of DL-APB (2amino-4-phosphonobutyric acid) on the ERG was also studied, as this compound has been shown to act selectively on ON-bipolar cells and thus eliminates the b-wave. ${ }^{17.18}$

\section{Drugs}

Ketamine and MK-801 were generous gifts from Parke-Davis Veterinary (Pontypool) and Merck, Sharpe and Dohme (Harlow), respectively. Dextromethorphan and APB were purchased from Sigma Chemicals.

\section{Results}

All experiments were individually performed with at least three animals. Typical representative observations are shown throughout, as a given treatment protocol resulted in very similar observations in all preparations in a group.

Figure 1 shows that the threshold and amplitude of both the a- and b-waves of retinae from rats which were not pretreated with ketamine were almost unaffected by the presence of up to $300 \mu \mathrm{M}$ ketamine in the perfusion medium $(n=5)$. Similarly, MK-801 (up to $200 \mu \mathrm{M})$ was without effect $(\mathrm{n}=3$ ). Figure 2 shows that, at concentrations of 100 and $200 \mu \mathrm{M},{ }^{16}$ dextromethorphan had no effect on the ERG, including the b-wave $(n=4)$. Only when the concentration of dextromethorphan was increased to 400 or $800 \mu \mathrm{M}$, did the drug exert a non-specific,

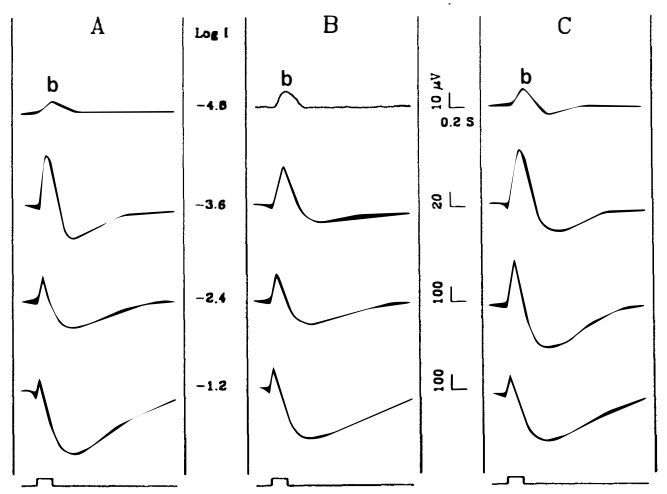

Fig. 1. Effect of ketamine on the ERG in vitro. The ERG was recorded in a dark-adapted, isolated rat retina. Ketamine was added to the perfusion medium to a final concentration of $150 \mu M$. A) Before, B) 4 minutes after, and C) 16 minutes after the application of ketamine. Note: increasing the concentration to $300 \mu \mathrm{M}$ did not change the responses (not shown). The sweep duration was $2 s$ and stimulus duration $0.2 s$, as indicated by the markers beneath the records. Responses obtained at different stimulus intensities ( $\log I=-4.8$ to -1.2 ) are shown. $b=b$-wave. 


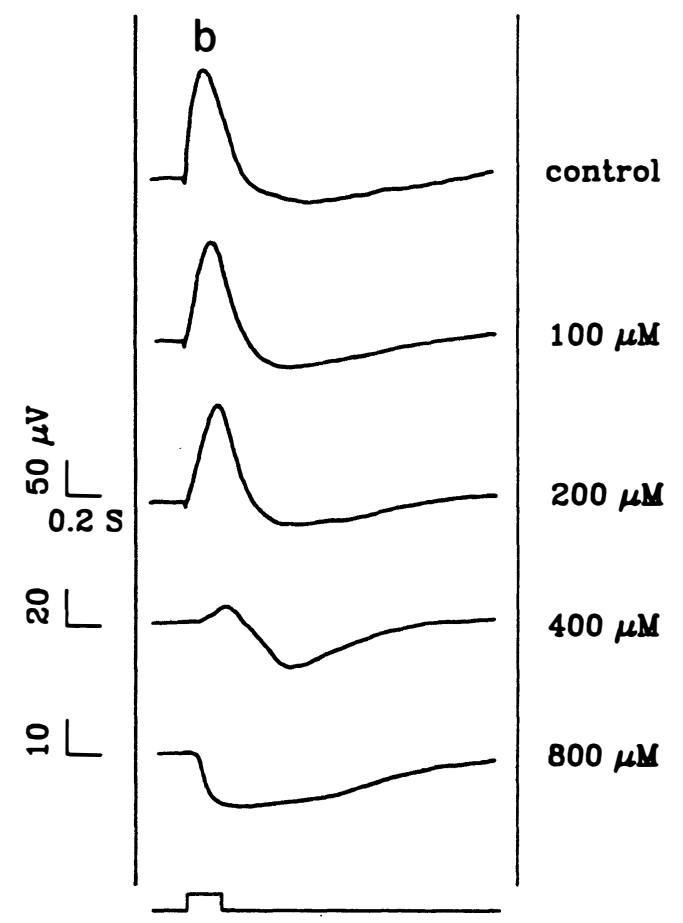

Fig. 2. Effect of dextromethorphan on the ERG in vitro. The ERG responses were recorded in a darkadapted, isolated rat retina before and 10 minutes after applications of dextromethorphan with increasing concentrations. Note: after the responses were suppressed, no recovery was observed throughout $2 \mathrm{~h}$ of reperfusion with non-dextromethorphan medium. The sweep duration was $2 \mathrm{~s}$ and stimulus duration $0.2 \mathrm{~s}$. Stimulus intensity: $\log I=-2.4 . b=b$-wave.

toxic effect on the responses-irreversibly suppressing both the b-wave and PIII component (Figure 2). Such high concentrations of dextromethorphan are known to exert nonspecific effects. ${ }^{16}$ In addition to the above observations, intraperitoneal injection of $100 \mathrm{mg} / \mathrm{kg}$ ketamine prior to tissue isolation had no direct effect on the a- or b-waves of retinae which had been isolated immediately $(\mathrm{n}=3)$.

In contrast to the effects seen with noncompetitive NMDA antagonists, addition of 10 to $100 \mu \mathrm{M}$ APB to the perfusion medium reversibly blocked the b-wave (Figure 3 ) $(n=3)$, thus showing that the system was responsive to a drug that acts selectively on ON-bipolar cells. ${ }^{17,18}$

To see if ketamine or dextromethorphan could prolong survival of the b-wave during postmortem anoxia, dark-adapted eyes, taken from rats previously injected with the drug, were left in the dark at room temperature for 30 and 60 minutes, respectively, and then the retinae were isolated. For comparison, eyes from rats without pretreatment with the drug were kept for the same periods of time. Following 30 minutes storage and subsequent perfusion with oxygenated medium, a b-wave gradually became manifest, taking about 10 minutes to reach its peak of $10 \mathrm{uV}$ : it then declined (Figure 4) $(n=3)$. No b-wave was seen in eyes which had been stored ex vivo for 60 minutes $(n=3)$. Prior intraperitoneal administration of ketamine or dextromethorphan made no difference to the above observations (Figure 4).

\section{Discussion}

In this study we have used the b-wave of the erg as an index of synaptic transmission from photoreceptors to second-order retinal cells. Although it is possible that the b-wave arises remotely from these second-order neurones, it is generally agreed that generation of the b-wave involves second-order neurones and that blockade of neurotransmission between photoreceptors and ON-bipolar cells abolishes the b-wave. ${ }^{4.5 .17 .18}$ The observation of partial recovery of the $b$-wave in the rat retina after 30 minutes anoxia (Figure 4) is in agreement with Winkler ${ }^{19}$ who reported that a b-wave could be regained by re-perfusion

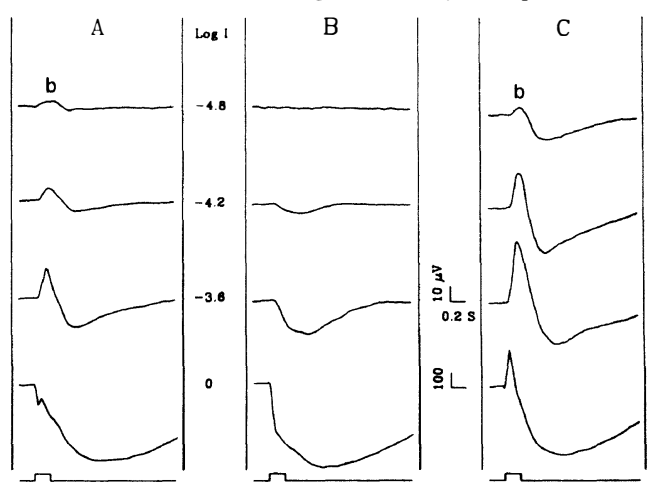

Fig. 3. Effect of $A P B$ on the b-wave in vitro. The $E R G$ was recorded in a dark-adapted, isolated rat retina. $A P B$ (final concentration $100 \mu \mathrm{M}$ ) was added to the perfusion medium, as described in the text. A) Before and B) 2 minutes after the application of $A P B$. $C) 2$ minutes after reperfusion with non- $A P B$ medium. Note: reducing the concentration of $A P B$ to $10 \mu \mathrm{M}$ produced similar effects on the $b$-wave. The sweep duration was $2 s$ and stimulus duration $0.2 s . b=b$ wave. 


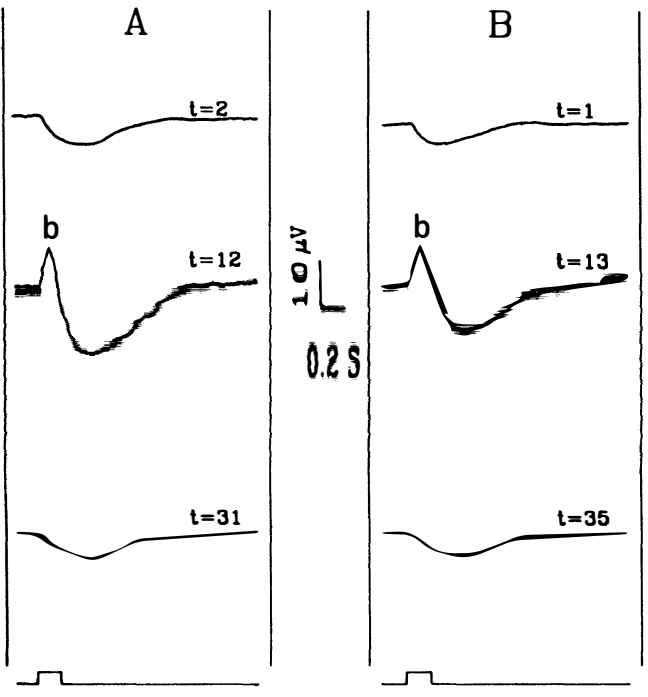

Fig. 4. In vivo pretreatment with ketamine. Darkadapted eyes were kept in the dark at room temperature for 30 minutes before measurement of the ERG: $A$ ) with and $B$ ) without prior intraperitoneal injection of ketamine (see the text for detail s.). The sweep duration was $2 s$ and stimulus duration $0.2 \mathrm{~s}$. Stimulus intensity: $\log I=-2.7 . t=$ time in minutes after the start of retinal perfusion. $b=b$-wave.

with oxygenated medium within 60 minutes anoxia, with no recovery if re-perfusion was commenced after this 60 minute period.

The present results indicate that ketamine, MK-801 and dextromethorphan have no direct effect on the b-wave in the rat retina (Figure 1, Figure 2). It is unlikely that the lack of effect on the b-wave is due to an inability of these drugs to penetrate the tissue, as APB was effective in our preparation. A more likely explanation is that the b-wave is not mediated via NMDA receptors. This is in agreement with Bloomfield and Dowling ${ }^{20}$ who found that NMDLA (N-methyl-DLaspartate) had no clear effect on rabbit ONbipolar cells, and with Coleman and Miller ${ }^{21}$ who showed that D-2-amino-5-phosphonovaleric and D-2-amino-7-phosphonoheptanoic acids (competitive NMDA antagonists) have no effect on the ERG in the mudpuppy. Thus the current observation confirms that there is little or no synaptically activated NMDAreceptor component to ON-bipolar cell responses to light in the vertebrate retina.

Since neither the b-wave nor PIII was better preserved postmortem by pre-treatment of rats with ketamine or dextromethorphan (Figure 4), and both responses were not affected by in vitro application of NMDA- receptor antagonists as discussed above, it is unlikely that their postmortem decline involves NMDA-receptor activation. This is, at first sight, somewhat surprising in view of the previous positive finding relating to the protection of the b-wave by dextromethorphan upon transient ischaemia in vivo. ${ }^{9}$ However, it is possible that different meehanisms underly it vivo ischaemia and postmottem anoxic damage or that dextromethorphan has other pharmacological effects on the rabbit retina than the proposed NMDA-receptor antagonism. According to Yoon and Marmor's observations in the rabbit, ${ }^{9}$ dextromethorphan prevents the photoreceptor cells, particularly the outer segments, from degenerative changes caused by 60 minutes' ischaemia. This phenomenon is interesting, but the mechanisms of neuro-protection may not be via a blockade of NMDA receptors of photoreceptor cells, because NMDA has been shown to be ineffective in inducing membrane potential changes in photoreceptor cells..$^{20.22}$

It has been shown in animals with a dual retinal circulation (such as the rat, ${ }^{23}$ gerbil, ${ }^{24} \mathrm{cat}^{25}$ and monkey ${ }^{26}$ ) that the initial degenerative changes, caused by ischaemia of the eye, occur in the inner retina. By contrast, in the rabbit $^{27.28}$ much of whose retina in effect only has a choroidal blood supply, interruption of the circulation causes ultrustructural abnormalities in photoreceptor outer segments within 30 minutes and in the inner segments and nuclei within two hours. Thus it seems that hypoxic damage to the retina, in terms of the sensitivity of geographic location, relates to its in vivo circulation conditions. It has also been suggested that dextromethorphan may induce an increase in cerebral blood flow or a decrease in cerebral metabolic requirements. ${ }^{29}$ Therefore, it is possible that the protection of rabbit photoreceptor cells by dextromethorphan against ischaemia is related to a reduction of tissue metabolic rate rather than a blockade of NMDA receptors. This requires further investigation by comparing various species and pharmacological agents.

We wish to thank Dr A. Leslie Holden for helpful discussions. J.C.H. was supported by The South Devon and Cornwall Institution for the Blind. Further financial support was provided by the British Retinitis Pigmentosa Society and the American Retinitis Pigmentosa Foundation. 
Key words: b-wave, dextromethorphan, electroretinogram, ketamine, MK-801, NMDA antagonist, rat retina, excitatory amino acids, neurotoxicity.

\section{References}

${ }^{1}$ Voaden MJ, Huang JC, Willmott NJ, Hussain AA: Functional recovery in human and rodent retinas in vitro. Biochem Soc Trans 1989, 17: 741-2.

${ }^{2}$ Huang JC, Voaden MJ, Marshall J: Survival of structure and function in postmortem rat and human retinas: rhodopsin regeneration, cGMP and the ERG. Curr Eye Res 1990, 9: 151-62.

${ }^{3}$ Huang JC, Voaden MJ, Marshall J, Kemp CM: Electrophysiologic characteristics of human and rat retinas in vitro. Doc Ophthalmol 1990, 76: 27-35.

${ }^{+}$Dowling JE: The Retina. Cambridge, Massachusetts, London. Belknap Press of Harvard Univ Press, 1987.

5 Stockton RA and Slaughter MM: B-wave of the electroretinogram: A reflection of ON-bipolar cell activity. J Gen Physiol 1989, 93: 101-22.

${ }^{6}$ Ehinger B and Dowling JE: Retinal neurocircuitry and transmission. In Bjorklund $\mathrm{A}$, Hokfelt $\mathrm{T}$. Swanson LW, eds. Handbook of Chemical Neuroanatomy, Vol 5, Amsterdam: Elsevier Science Publishers BV 1987: 389-446.

${ }^{7}$ Massey SC and Redburn DA: Transmitter circuits in the vertebrate retina. Prog Neurobiol 1987, 28: 55-96.

${ }^{8}$ Voaden MJ: Glutamine and its neuroactive derivatives in the retina. In Kvamme E ed. Glutamine and Glutamate in Mammals, Vol 2, Boca Raton. Florida: CRC Press 1988: 71-88.

${ }^{9}$ Yoon HY and Marmor MF: Dextromethorphan protects retina against ischaemic injury in vivo. Arch Ophthalmol 1989, 107: 409-11.

${ }^{10}$ Drejer J, Sheardown M, Nielsen EO, Honore T: Glycine reverses the effect of HA-966 on NMDA responses in cultured rat cortical neurons and in chick retina. Neurosci Lett 1989, 98: 333-8.

"Zeevalk GD and Nicklas WJ: Acute excitotoxicity in chick retina caused by the unusual amino acids BOAA and BMAA: Effects of MK801 and kynurenate. Neurosci Lett 1989, 102: 284-90.

${ }^{12}$ Lawrence D and Livingston A: Opiate-like analgesic activity in general anaesthetics. Br J Pharmacol 1981, 73: 435-42.

${ }^{1.3}$ Prince DA and Feeser HR: Dextromethorphan protects against cerebral infarction in a rat model of hypoxia-ischemia. Neurosci Lett 1988, 85: 291-6.

${ }^{14}$ Marcoux FW, Probert AW, Goodrich JE, Dominick MA: The NMDA anatagonist, ketamine, blocks hypoxia-induced calcium accumulation in cultured cortical neurons and prevents ischemic hippocampal cell injury. In Cavalheiro EA.
Lehmann, J, Turski L, eds. Frontiers in Excitatory Amino Acid Research, New York: Alan R Liss Inc 1988: 683-686.

${ }^{15}$ Anderton PJ and Millar TJ: MK 801-induced antagonism of NMDA preferring excitatory amino acid receptors in horizontal cells of the turtle retina. Neurosci Lett 1989, 101: 331-6.

${ }^{16}$ Choi DW, Peters S, Viseskul V: Dextrorphan and levorphanol selectively block $\mathrm{N}$-methyl-D-aspartate receptor-mediated neurotoxicity on cortical neurones. J Pharmacol Exp Ther 1987, 242: 713-20.

${ }^{17}$ Porciatti V, Bagnoli P, Alesci R, Fontanest G: Pharmacological dissociation of the b-wave and pattern electroretinogram. Doc Ophthalmol 1987, 65: $377-83$.

is Powers M, DeMarco P, Bilotta J: APB eliminates ERG b-wave but not optic nerve "ON" response in goldfish. Invest Ophthalmol Vis Sci (suppl) 1988, 29: 104 .

${ }^{19}$ Winkler BS: The electroretinogram of the isolated rat retina. Vis Res 1972, 12: 1183-98.

${ }^{21}$ Bloomfield SA and Dowling JE: Roles of aspartate and glutamate in synaptic tranmission in rabbit retina. I. Outer plexiform layer. J Neurophysiol 1985, 53: 699-713.

${ }^{2}$ Coleman PA and Miller RF: Do N-methyl-D-aspartate receptors mediate synaptic response in the Mudpuppy retina? J Neurosci 1988, 8: 4728-33.

$\because$ Tachibana M and Kancko A: L-Glutamate-induced depolarization in solitary photoreceptors: A process that may contribute to the interaction between photoreceptors in situ. Proc Natl Acad Sci USA 1988, 85: 5315-19.

23 Turnbull W: Effects of experimental retinal anaemia in rats. Arch Ophthalmol 1950, 43: 9-31.

${ }^{2+}$ Levine $\mathrm{S}$ and Payan $\mathrm{H}$ : Effects of ischaemia and other procedures on the brain and retina of the gerbil. Exp Neurol 1966, 16: 255-62.

${ }^{25}$ Reinecke RD, Kuwabara T. Cogan DG, Weis DR: Retinal vascular patterns. V. Experimental ischemia of the cat eve. Arch Ophthalmol 1962, 67: $470-5$.

26 Fujino T and Hamasaki DI: Effect of intraocular pressure on the electroretinogram. Arch Ophthalmol 1967. 78: 757-65.

${ }^{27}$ Johnson NF and Grierson I: Postmortem changes in the rabbit retina. Acta Ophthalmol 1976, 54: $529-41$.

in Johnson NF and Foulds WS: The effects of total acute ischemia on the structure of the rabbit retina. Exp Eye Res 1978, 27: 45-59.

2" George CP, Goldberg MP, Choi DW, Steinberg GK: Dextromethorphan reduces neocortical ischemic neuronal damage in vivo. Brain Res 1988, 440: 375-9. 